\title{
PRODUÇÃO DE POLI (ÁCIDO LÁTICO) A PARTIR DO SORO DO LEITE
}

\section{PRODUCTION OF POLY (LACTIC ACID) THROUGH WHEY}

\author{
M. A. HORBAN ${ }^{1}$, A. A., SILVA ${ }^{1}$, M. P. MAYDL ${ }^{1}$, R. CASTELLA ${ }^{1}$ e C. E. LUNELLI ${ }^{1}$ \\ ${ }^{1}$ Pontifícia Universidade Católica do Paraná, Departamento de Engenharia Química, Brasil \\ E-mail: marcoahorban@gmail.com
}

article info

Article history:

Received 6 July 2016

Accepted 3 January 2017

Available online 6 January 2017
PALAVRAS-CHAVE: Poli (ácido lático); PLA; Soro do leite; Lactídeo; Polimerização por abertura de anel.

KEYWORDS: Poly (lactic acid); PLA; Whey; Lactide; Ring-opening polymerization.

RESUMO: O poli (ácido lático) (PLA) é um polímero derivado de fontes renováveis que, devido à suas características mecânicas e baixa toxicidade, tem uma vasta área de aplicação. Atualmente, o ácido lático utilizado na produção de PLA é obtido através da fermentação de vegetais ricos em amido, porém, com o intuito de tornar o processo mais economicamente viável, o uso de diversos rejeitos industriais tem sido estudado. Assim, foi proposta neste trabalho uma planta industrial para produção de PLA empregando o soro do leite, um rejeito da indústria de laticínio. O processo é dividido em duas etapas: produção de ácido lático e formação do PLA. A primeira consiste na preparação do soro, fermentação da lactose e purificação do ácido lático. Já a segunda etapa é constituída da formação do oligômero, produção e purificação do lactídeo e, por ultimo, polimerização por abertura de anel, originando um poli (ácido lático) de alta massa molar.

\begin{abstract}
The poly (lactic acid) (PLA) is a polymer derived from renewable sources that, because of its mechanical characteristics and low toxicity, has a wide application area. Currently, the lactic acid utilized in the production of PLA is obtain through the fermentation of starch rich vegetables, however, with the intention of turn the process more economically viable, the use of several industrial wastes have been study. Thus, it was propose in this work an industrial plant for production of PLA employing whey, a dairy industry waste. The process was divided in two stages: production of lactic acid and formation of PLA. The first consist in preparing the whey, fermentation of lactose and purification of lactic acid. The second stage is constituted of the oligomer formation, production and purification of lactide and, at last, ring-opening polymerization, originating a poly (lactic acid) of high molecular weight.
\end{abstract}

\section{INTRODUÇÃO}

O poli (ácido lático) (PLA) é um polímero termoplástico que, devido à suas características mecânicas e baixa toxicidade, tem grande versatilidade, sendo empregado desde embalagens alimentícias até implantes médicos (SAINI et. al., 2016). Além de características físicas interessantes, o PLA também apresenta alta biodegradabilidade e não utiliza derivados petroquímicos como matéria-prima, mas sim o ácido lático, um produto obtido da fermentação de biomassa (MURARIU; DUBOIS, 2016). 
O ácido lático (ácido 2-hidroxipropanoico) pode ser obtido através de ação biológica, via fermentação, ou por meio de síntese química. A rota fermentativa pode produzir isômeros puros $\mathrm{L}(+)$ e $\mathrm{D}(-)$ de ácido lático, além da mistura racêmica $\mathrm{DL}$, enquanto a rota química produz apenas uma mistura racêmica. $O$ tipo do microrganismo empregado na fermentação determina qual isômero é produzido (BERNARDO, 2014). Devido à vantagem econômica, aproximadamente $90 \%$ de todo ácido lático produzido no mundo é proveniente de fermentação (HAMAD et. al., 2015).

A biomassa empregada como matéria-prima para produção de ácido lático através da fermentação é geralmente um conjunto de vegetais ricos em amido, porém, neste trabalho é proposta a utilização da lactose proveniente do soro do leite que é um resíduo da produção de queijo potencialmente poluente para o solo e corpos d'água (COSTA et. al., 2014).

Segundo Siqueira et. al. (2013), cerca de 50\% do soro do leite produzido no país não é reaproveitado, o que implica um grande desperdício de nutrientes. Desenvolver novos usos para esse rejeito é de crucial importância para reduzir seu desperdício e o papel do soro como problema ambiental.

O soro do leite é tido como poluente devido sua alta concentração de matéria orgânica, principalmente a lactose, que favorece o crescimento bacteriano ao ser descartado sem tratamento em corpos receptores, o que por sua vez acaba por diminuir a quantidade de oxigênio diluído no corpo d'agua (PRAZERES et. al., 2012).

Sendo assim, existe um grande interesse em reaproveitar o soro do leite, tendo em vista seu alto valor de DBO (30.000 a $60.000 \mathrm{mg} . \mathrm{L}^{-1}$ ) (ROHLFES et. al., 2014), que acaba refletindo num maior custo no tratamento desse efluente e num encarecimento dos produtos derivados do leite em decorrência disso. É possível afirmar que a fermentação da lactose do soro do leite para a produção de ácido lático é uma alternativa para o problema ambiental que o soro do leite representa.

Citam-se duas rotas tecnológicas principais para a polimerização do ácido lático: a polimerização por condensação direta e a polimerização por abertura de anel de lactídeo (PRETULA et. al., 2016). A primeira tem como sua principal vantagem a simplicidade tecnológica e seu baixo custo operacional, porém o PLA obtido é de uma menor massa molar. A segunda rota, apesar de mais complexa, apresenta um produto final de alta massa molar e é amplamente utilizada pelos maiores produtores de PLA no mercado (SLOMKOWSKI et. al., 2014). Essa rota utiliza de um composto intermediário, o lactídeo, para produzir um polímero final de alta massa molar (CASTRO-AGUIRRE et. al., 2016).

Apesar de novos processos de policondensação, como polimerização por desidratação azeotrópica, serem capazes de atingir uma alta massa molar, essas técnicas ainda são vistas como economicamente inviáveis para a produção industrial (FARAH et. al., 2016). A Figura 1 representa as principais rotas de polimerização do ácido lático: 


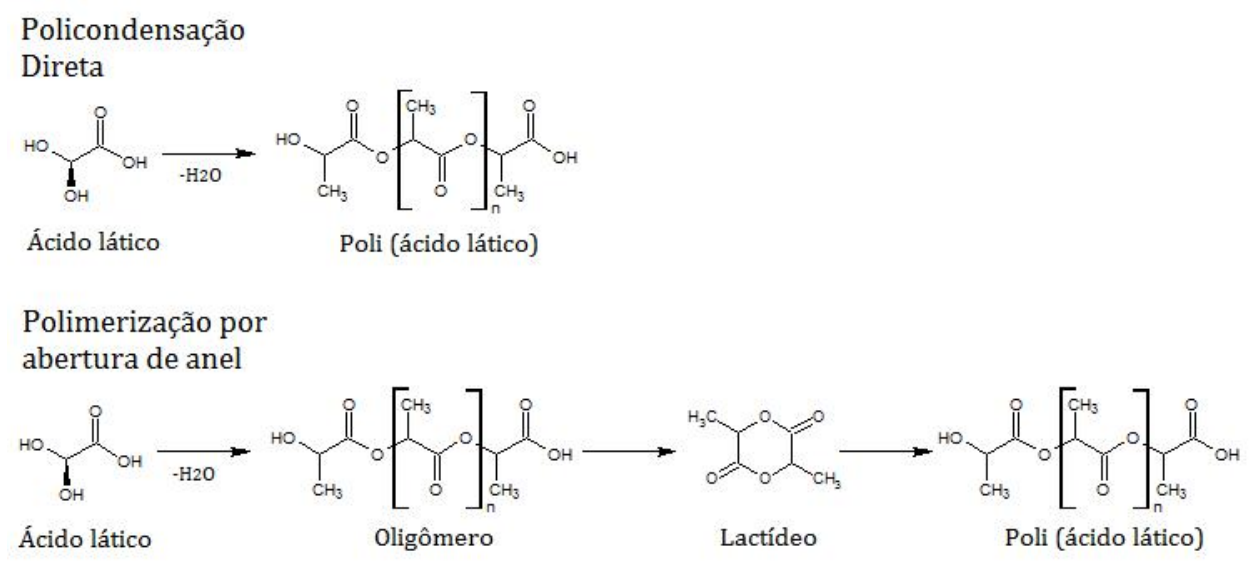

Figura 1 - Rotas de síntese de PLA.

Este estudo teve como objetivo propor uma rota tecnológica para a fabricação de poli (ácido lático) de alta massa molar, descrevendo os principais reatores, operações unitárias, vasos de processo e demais equipamentos. A rota abordada é a fermentativa, objetivando a obtenção de ácido lático com posterior polimerização através da abertura de anel do lactídeo, sendo empregado catalisador metálico óxido de estanho.

\section{MATERIAIS E MÉTODOS}

Foi proposta uma rota tecnológica utilizando princípios de balanço de massa e energia, cinética química, instrumentação e controle, entre outros. Procurando assim, desenvolver um diagrama de processos contendo equipamentos, parâmetros de operação e seus devidos controles.

\section{RESULTADOS E DISCUSSÃO}

O projeto foi dividido em duas plantas de operação: a etapa de obtenção e purificação do ácido lático por rota fermentativa e a etapa de polimerização por abertura de anel do lactídeo. A primeira tem como objetivo a conversão da lactose presente do soro do leite em ácido lático, assim como sua purificação e a segunda consiste na polimerização do ácido lático através da substância intermediária lactídeo.

\subsection{Obtenção e purificação do ácido lático}

A primeira etapa do processo visa o preparo do meio fermentativo, a produção de ácido lático através de fermentação e a posterior purificação do ácido lático. A Figura 2 ilustra o processo completo dessa etapa: 


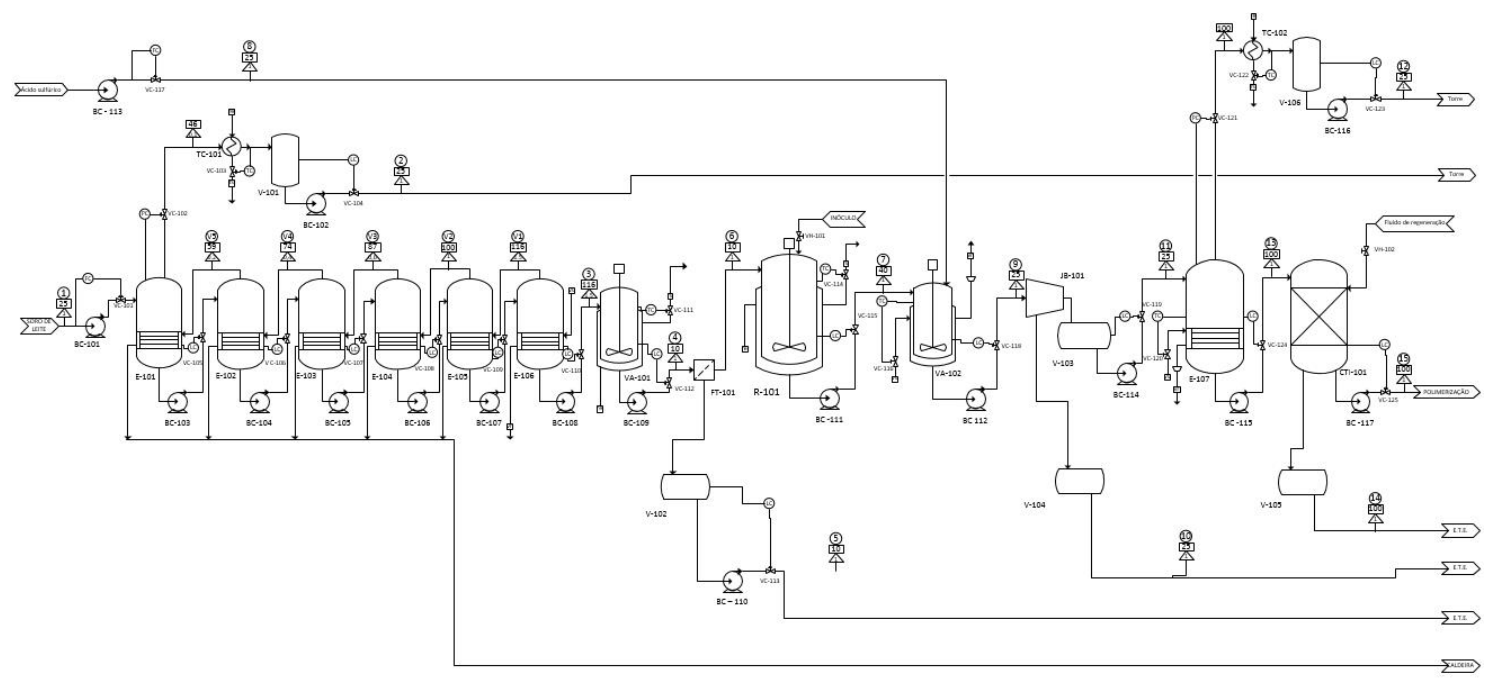

Figura 2 - Produção de ácido lático por fermentação.

Primeiramente, é necessário preparar o soro do leite para atender condições ideais que favoreçam a fermentação. O soro do leite é composto majoritariamente de água, sendo assim, é feito a retirada do excesso de água, aumentando a concentração de lactose da solução até uma quantidade tida como ideal para ocorrer a fermentação. Isto é feito através de um sistema de evaporadores de seis efeitos (E-101 até E-106) operando em contracorrente. A Figura 3 a seguir representa o arranjo de evaporadores de múltiplos efeitos:

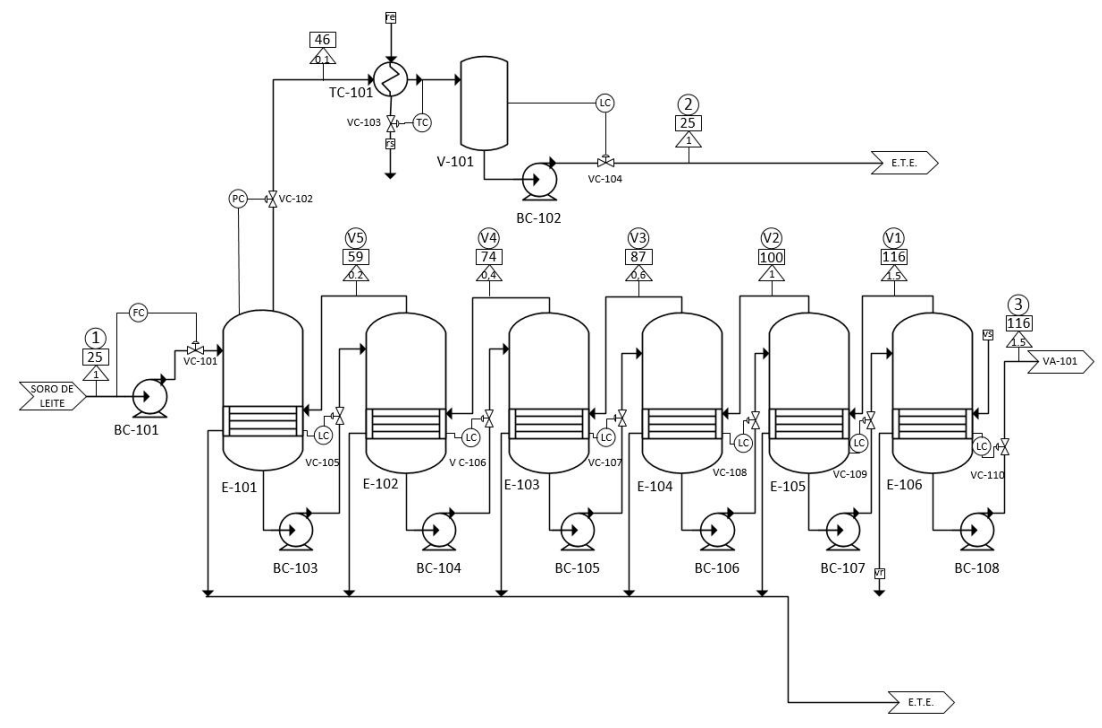

Figura 3 - Sistema de evaporadores contracorrente.

Foi escolhido um sistema contracorrente frente a um concorrente devido à sua maior economia energética, assim como descrito por Earl (1983). Em cada efeito existe um controle de nível, a fim de assegurar as condições ideais de operação. No efeito E-101 existe um 
controle de pressão que age na saída de vapor de topo, garantindo que o processo opere sobre vácuo. É descrito por Walas et. al. (2012) que a disposição dos vasos de processo depende de seu conteúdo. Se a corrente que passa pelo vaso é líquida, o vaso deve ser horizontal. No caso de mistura líquido/vapor, deve-se utilizar um vaso vertical. Essa regra é usada no decorrer de todo o trabalho. Portanto o vaso V-101, que capta o vapor condensado no trocador de calor TC-101, é disposto verticalmente e tem um controle de nível a fim de garantir a operação da bomba BC-101.

Retirado o excesso de água, é necessário retirar gordura e proteína presentes no soro. A corrente efluente do sistema de evaporadores passa por um vaso agitado resfriado VA-101. A queda brusca de temperatura causa a coagulação das proteínas e da gordura presentes no soro, permitindo a retirada desses materiais através do filtro FT-101. O processo está exemplificado na Figura 4:

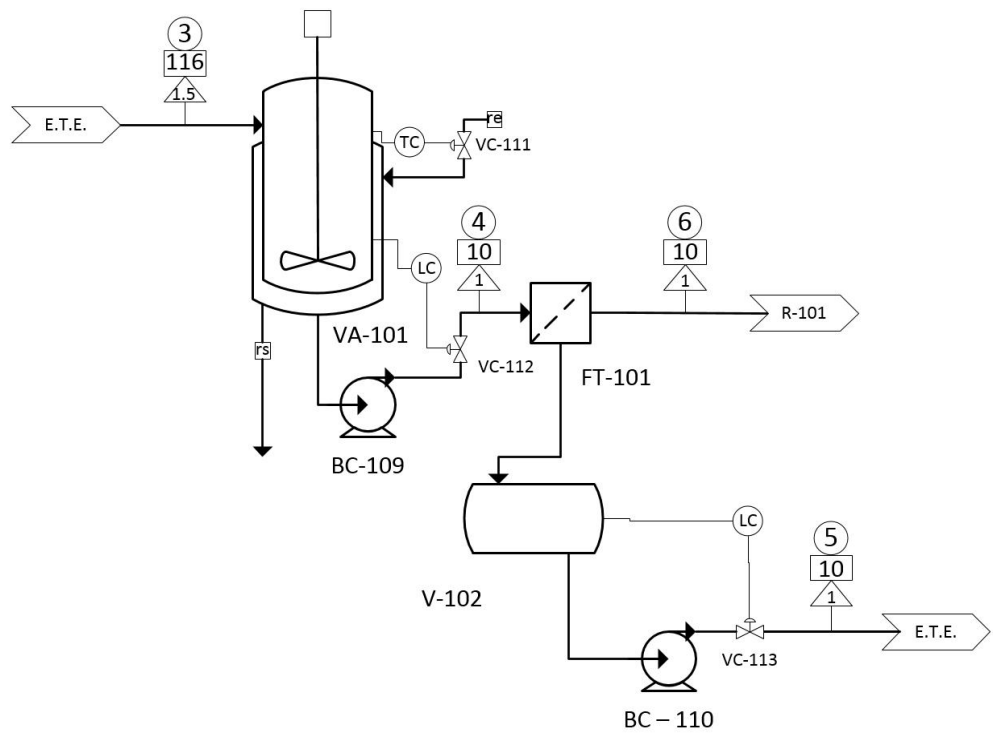

Figura 4 - Retirada de proteínas e gordura.

O resfriamento é realizado por uma corrente de água de processo alimentada à camisa do vaso e o controle da temperatura é feito através dessa corrente. O nível do tanque é controlado através da vazão de soro na corrente de fundo.

Com a retirada de gordura, proteína e excesso de água, a solução está pronta para passar pela etapa de fermentação. A solução é alimentada a um reator R-101 onde entra em contato com a bactéria Lactobaccillus helveticus, responsável pela conversão da lactose em ácido lático. O reator de fermentação está representado na Figura 5: 


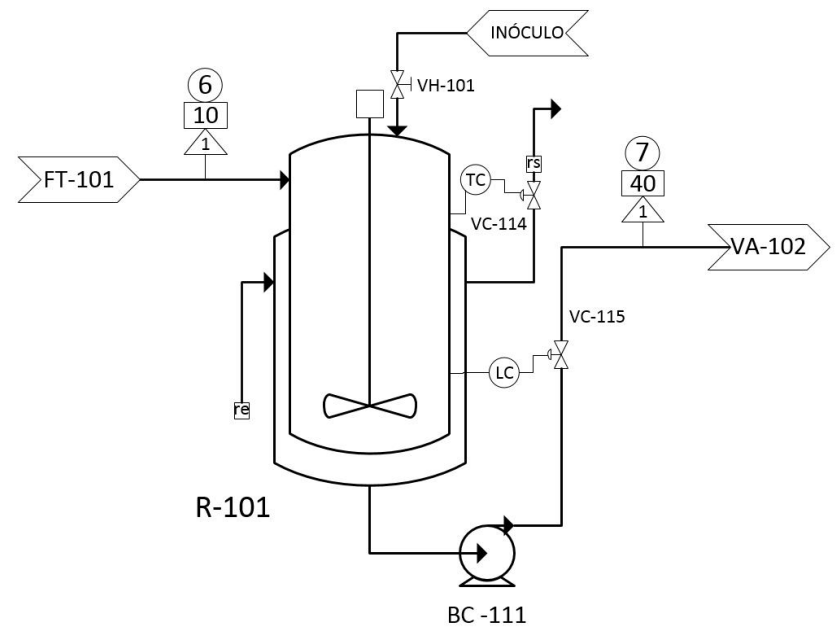

Figura 5 - Reator de fermentação.

O reator é encamisado e agitado mecanicamente, opera em batelada de 36 horas mantendo uma temperatura constante de $40^{\circ} \mathrm{C}$ a fim de garantir uma alta conversão de lactose em ácido lático. O controle de temperatura é realizado através da alimentação de água de processo na camisa.

Decorrido o tempo de fermentação, a solução necessita ser desmineralizada, operação realizada através do vaso agitado VA-102 onde a solução entra em contato com ácido sulfúrico que fará com que os sólidos solúveis do leite precipitem, permitindo a sua retirada pela centrífuga JB-101. A Figura 6 representa essa etapa:

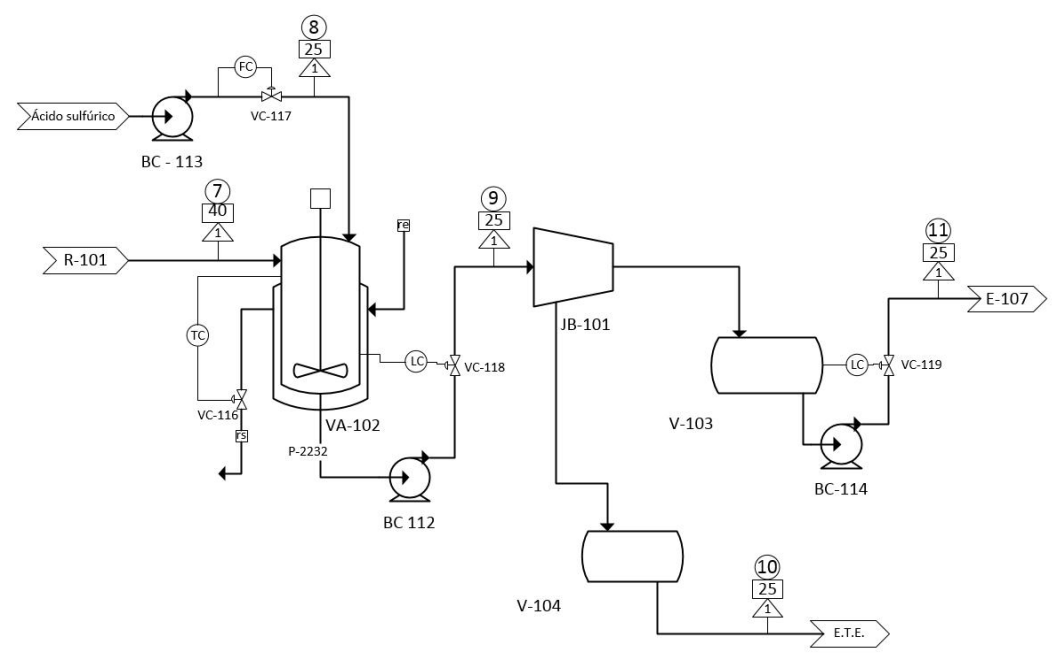

Figura 6 - Desmineralização da solução.

O vaso VA-102 é agitado mecanicamente e resfriado através de uma camisa por onde circula água de refrigeração. A temperatura no vaso é controlada através da vazão de água de 
refrigeração que passa por dentro da camisa. Também há um controle de nível no vaso. Após a centrífuga JB-101 existe um vaso de processo (V-103), responsável por coletar o líquido centrifugado e manter o nível de operação da bomba BC-112.

A corrente segue para um evaporador de simples efeito E-107 com o intuito de retirar o excesso de água. O controle de temperatura é realizado através da vazão de vapor que passa pelo trocador de calor dentro do evaporador. Existe também um controle de nível atuando através da corrente e fundo e um controle de pressão atuando na corrente de topo. Ainda existe um conjunto de trocadores de calor e vaso de operação, responsáveis por coletar a água evaporada. A Figura 7 demonstra os equipamentos descritos acima:

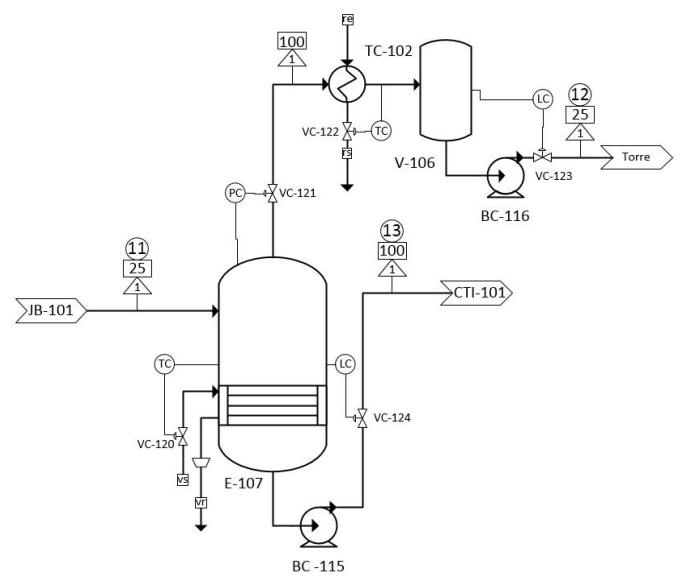

Figura 7 - Evaporador simples.

Por último, é necessário recuperar o ácido lático do caldo fermentado. É instalada uma coluna de troca iônica CTI-101 que apresenta como função a retirada da lactose não reagida na etapa de fermentação. Este processo é realizado através de uma resina presente dentro da coluna que tem retém a lactose e permite a passagem do ácido lático. A figura 8 demonstra este equipamento:

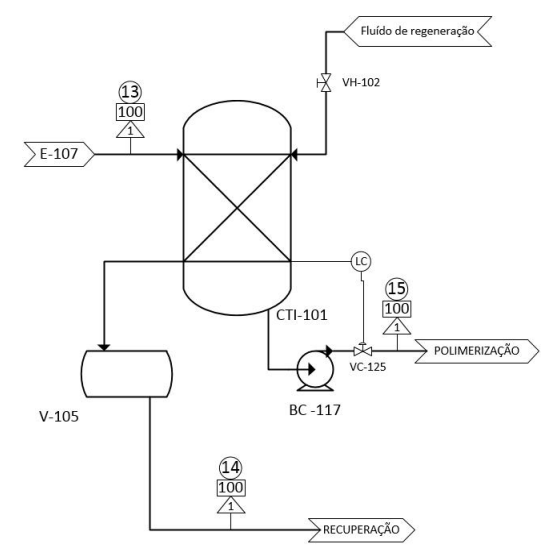

Figura 8 - Coluna de troca iônica. 
Há um controle de nível na coluna e uma corrente paralela de fluido de regeneração a qual deve ser acionada para a retirada da lactose retida pela resina. Ao final dessa etapa, espera-se obter uma solução de ácido lático concentrado com um alto grau de pureza.

\subsection{Polimerização por abertura e anel do lactídeo}

A rota de polimerização por abertura de anel do lactídeo tem três etapas: formação de oligômero através da polimerização por condensação direta do ácido lático, formação do lactídeo através da despolimerização do oligômero e por último a formação de PLA através da polimerização por abertura de anel do lactídeo (LOPES et. al. 2014). A Figura 9 demonstra o processo completo de polimerização do ácido lático:

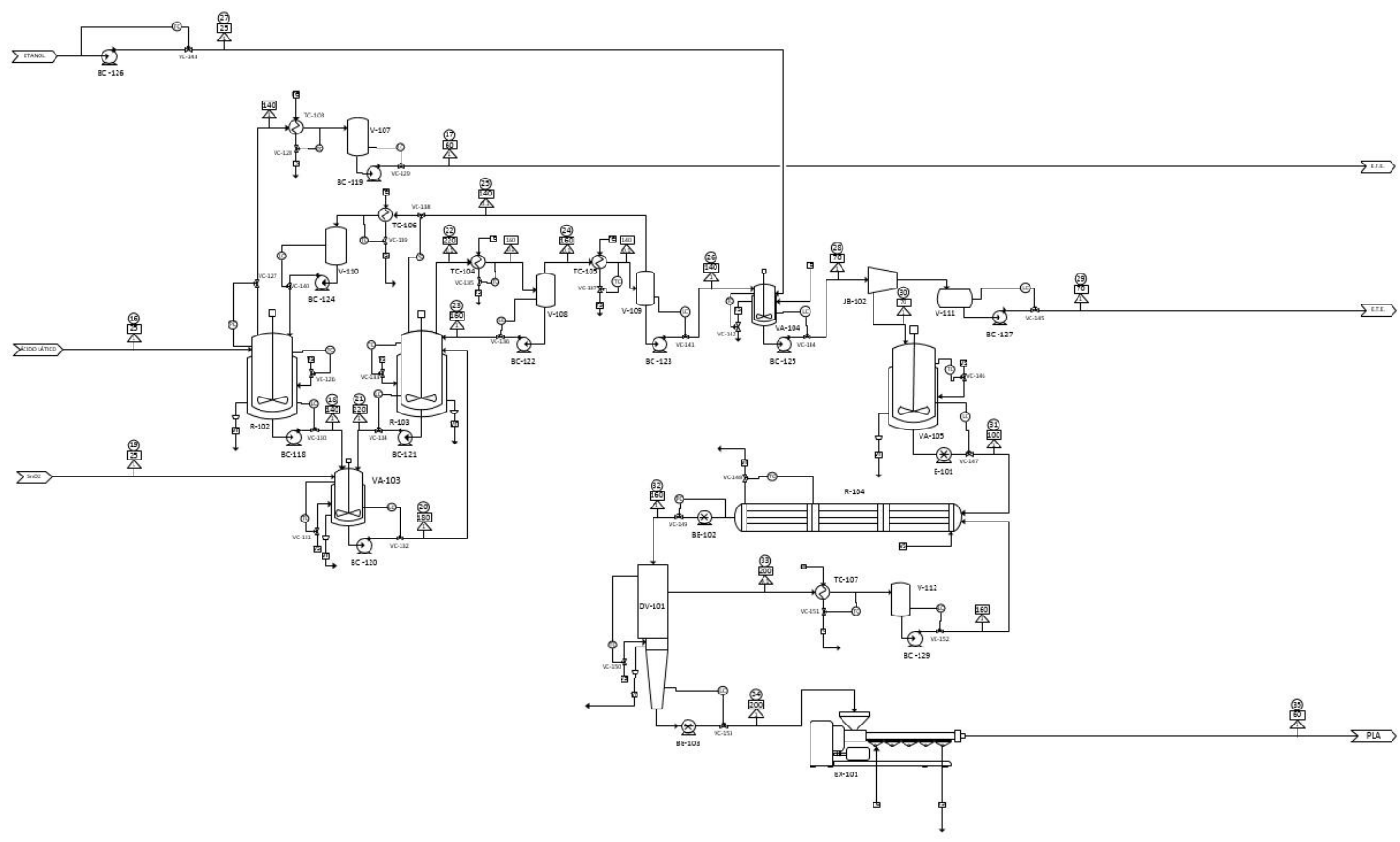

Figura 9 - Produção de PLA através de polimerização por abertura de anel do lactídeo.

O processo de polimerização, assim descrito por Yoshida (2012), se inicia em um reator CSTR R-102, responsável por fazer a polimerização por condensação direta do ácido lático, gerando um polímero de baixa massa molar denominado oligômero. A reação de polimerização por condensação é descrita por Canevarolo (2006) como sendo a formação de cadeias poliméricas através da eliminação de um subproduto de baixa massa molar, tal como a água, amônia, ácido clorídrico, entre outros. No caso do ácido lático, a polimerização ocorre com a eliminação de moléculas água. A Figura 10 a seguir representa o reator R-102: 


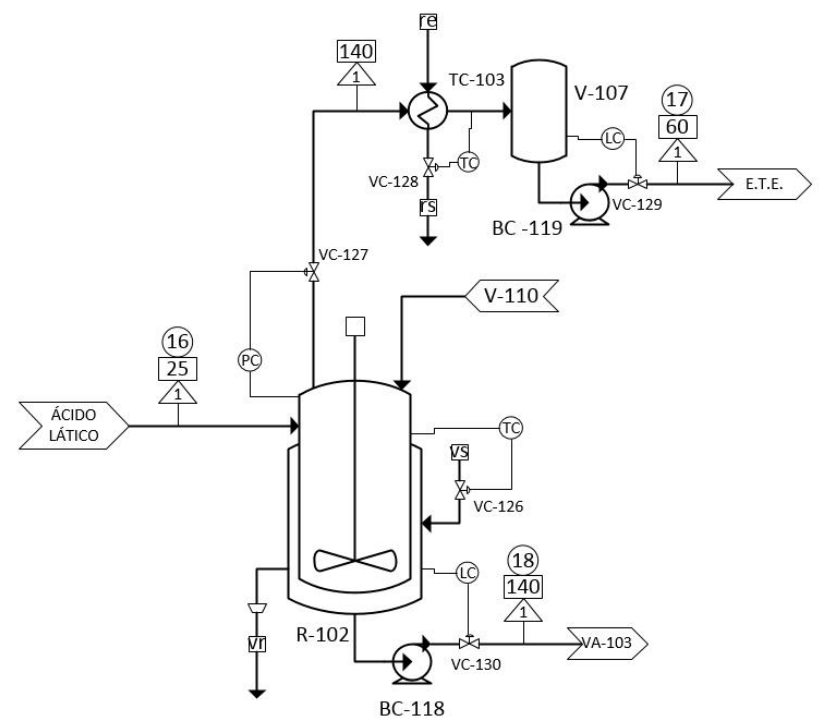

Figura 10 - Reator de condensação direta.

Para favorecer a polimerização do ácido lático, a água gerada durante o processo deve ser continuamente retirada (YOSHIMARA et. al., 2016). Isso ocorre através de uma corrente de vapor no topo do reator cujo é equipado com um agitador mecânico e uma camisa de aquecimento por onde passa vapor saturado. O controle de temperatura é realizado através da alimentação de vapor à camisa e o controle de pressão atua na corrente de topo do reator, sendo este acoplado a um sistema de trocador de calor e vaso vertical a fim de recolher a água retirada do processo. Por fim um controle de nível no vaso V-107 garante a operação da bomba.

Após a etapa de formação do oligômero, a corrente segue em direção a um vaso agitado VA-103 onde a solução será misturada com o catalisador (óxido de estanho) e aquecida até uma temperatura ideal para que ocorra a despolimerização no reator CSTR R103. Existem duas correntes efluentes do reator, uma de refluxo, responsável por transportar o catalizador e parte do oligômero não reagido para o vaso VA-103, e uma corrente de topo, formada por uma mistura gasosa de lactídeo, água, ácido lático não reagido no reator R-102 e pequenas cadeias de oligômero.

O vaso VA-103 apresenta um controle de temperatura operando na vazão de vapor saturado na camisa e um controle de nível na corrente de fundo. O reator apresenta controle de temperatura operando na vazão de vapor saturado na camisa, de nível operando na corrente de reciclo para o vaso VA-103 e um controle de pressão operando na última corrente de vapor associada ao reator. Com a quebra das ligações químicas do oligômero, os monômeros se rearranjam como lactídeo, o diéster cíclico do ácido lático (YOSHIDA, 2012). A figura 11 representa o vaso agitado VA-103 e reator R-103: 


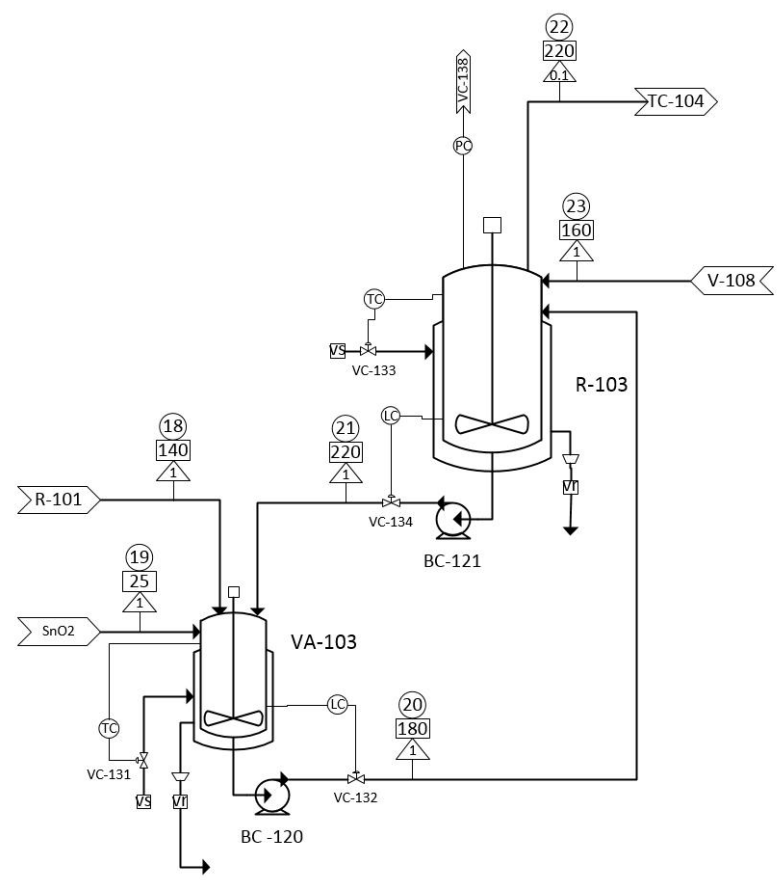

Figura 11 - Reator de despolimerização e vaso agitado.

Sendo necessário separar o lactídeo das impurezas, a corrente efluente do reator R-103 passa por um sistema de três conjuntos de trocadores de calor e vasos de processo ligados em série. Como representado na figura 12 :

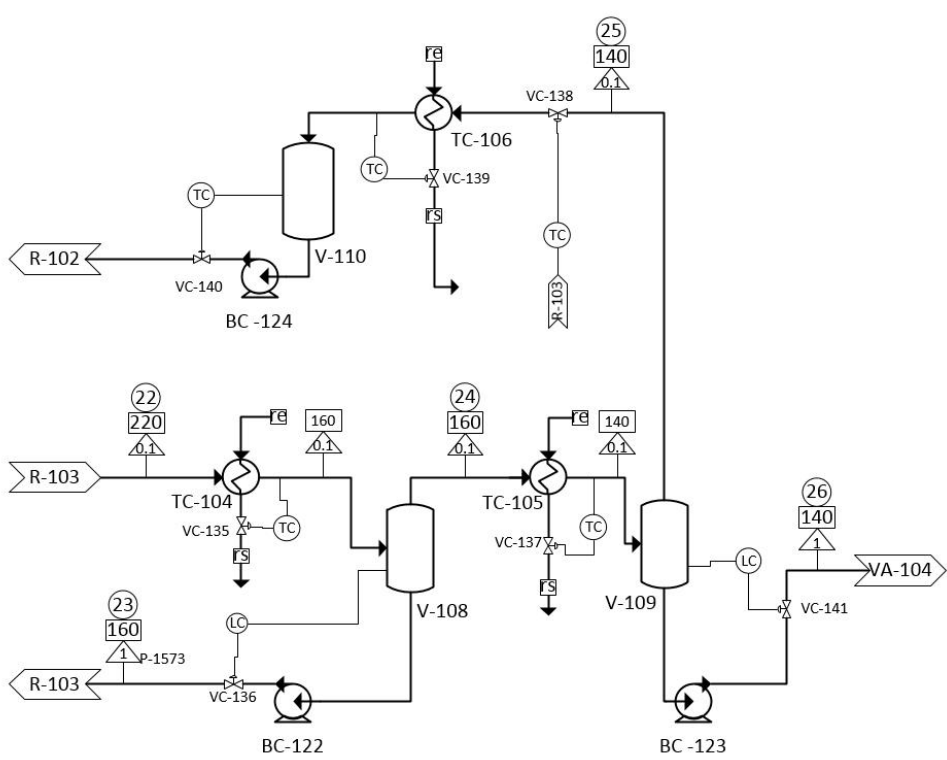

Figura 12 - Sistema de trocadores de calor e vasos de processo. 
Cada trocador de calor opera em uma faixa de temperatura a fim de efetuar a separação através da diferença de pontos de fusão. O primeiro conjunto de trocadores de calor e vaso (TC-104 e V-108, respectivamente) tem como objetivo a condensação e coleta do oligômero. Uma corrente de fundo no vaso V-108 faz o reciclo do oligômero para o reator R-103. Um controle de nível age sobre esta corrente, garantindo o nível de operação do vaso. O segundo trocador de calor TC-105 opera em uma faixa de temperatura que favorece a condensação de parte da água presente na corrente e do lactídeo. O condensado é então coletado pelo vaso V109 e enviado através de uma corrente de fundo para a próxima etapa. Um controle de nível operando na corrente de fundo garante o nível de operação do vaso. Por último, o ácido lático e o restante de água são coletados por um terceiro conjunto de trocadores de calor e vaso de processo (TC-106 e V-110) e reciclados para o reator R-102. Assim como descrito por WALAS et. al. (1988), os vasos que operam com mistura de líquido/gás são posicionados verticalmente.

Retiradas as impurezas do lactídeo, é necessário realizar sua recristalização. O processo é descrito por Yoshida (2012) que determina que o processo deve ocorrer em temperatura de $10^{\circ} \mathrm{C}$ na presença de etanol. A solução lactídeo/água é alimentada a um vaso agitado e encamisado (VA-104) onde também é alimentado etanol. Dado o tempo da cristalização a corrente segue para uma centrífuga JB-102. A Figura 13 abaixo representa o processo:

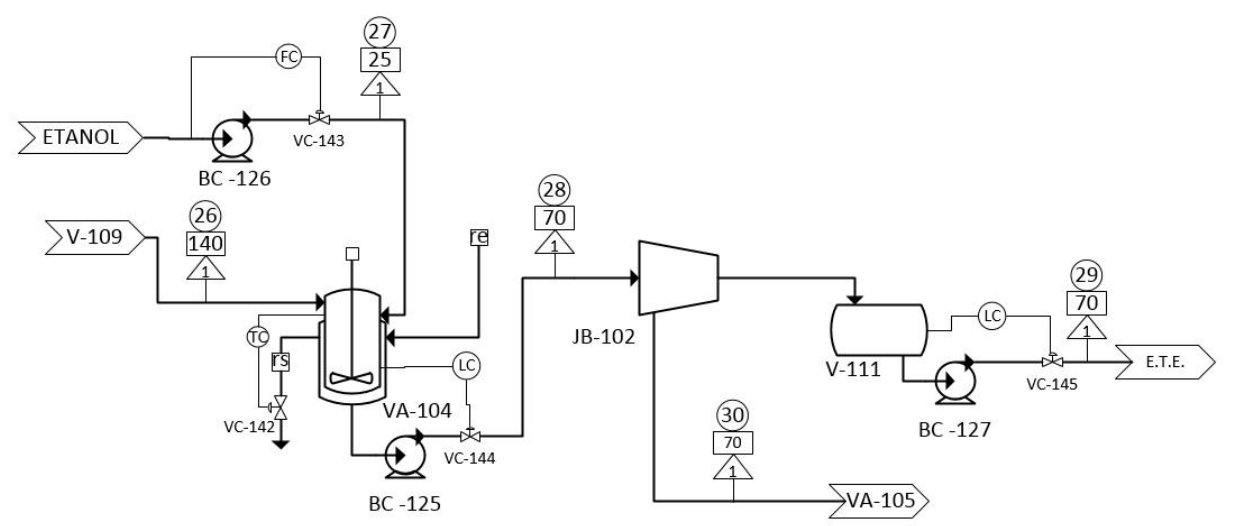

Figura 13 - Cristalização do lactídeo.

O controle da temperatura no vaso é realizado através da vazão de água de refrigeração passada por dentro da camisa na qual existe um controle de nível atuando na corrente de fundo do vaso. Após a centrífuga JB-102 existe um vaso de processo (V-111) que coleta o etanol e água retirados após a centrifugação. Existe um controle de nível atuando nesse vaso a fim de garantir as condições de operação da bomba BC-127.

O lactídeo cristalizado é então transportado para um vaso agitado VA-105 que tem como função aquecer a solução até uma temperatura ideal para que ocorra a polimerização do lactídeo. A solução aquecida é então transportada para um reator tubular R-104, como demonstrado na Figura 14: 


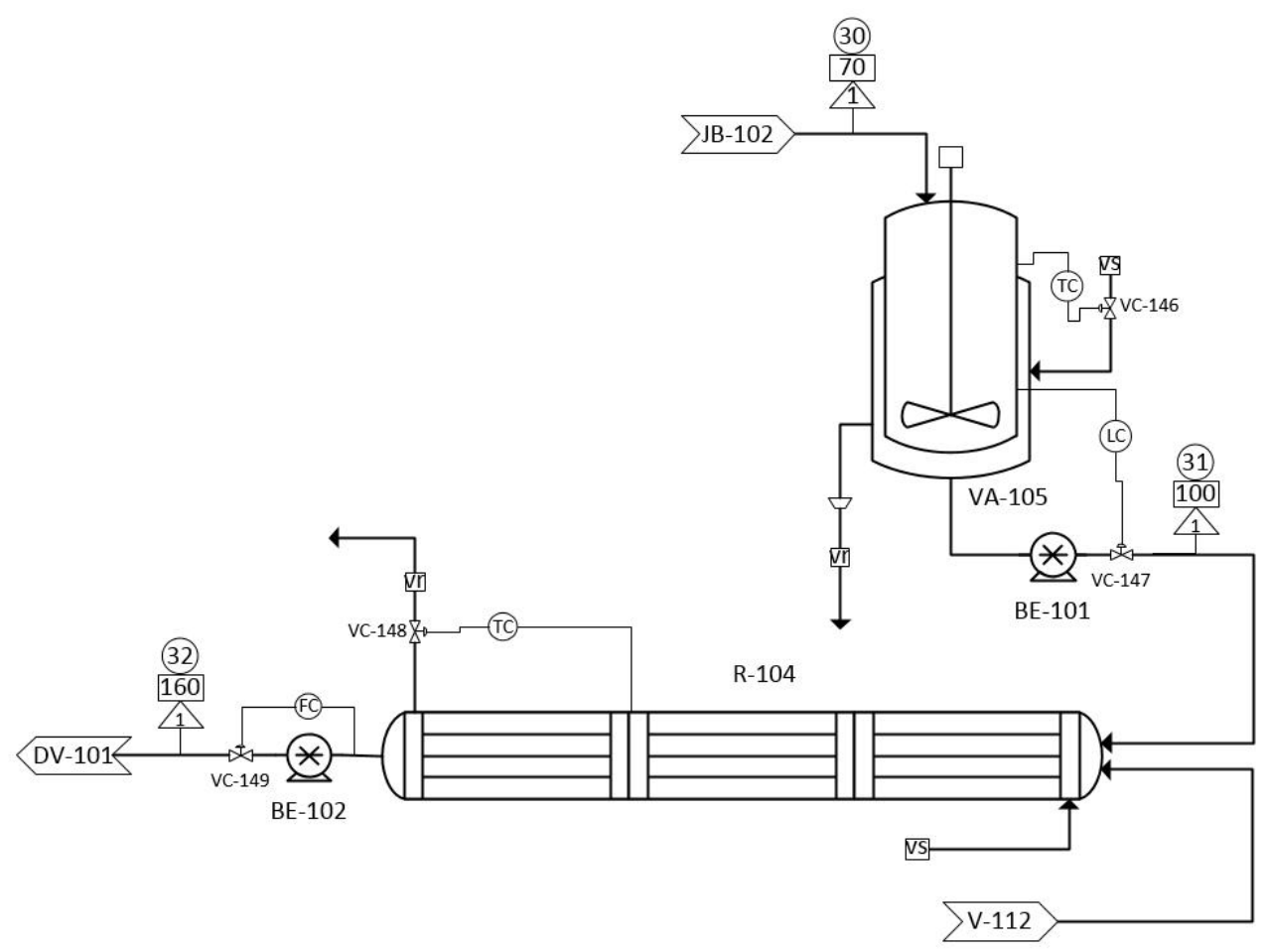

Figura 14 - Reator de polimerização tubular e vaso agitado.

O vaso VA-105 é equipado com um controle de temperatura que age na corrente de alimentação de vapor na camisa e um controle de nível que age na corrente de fundo do vaso. $\mathrm{O}$ transporte do lactídeo é feito através de uma bomba de engrenagem BE-101 que permite um maior controle da taxa de alimentação no reator, incidindo num melhor controle sobre o tempo de residência, que por sua vez resultam em uma produção de PLA com cadeias poliméricas mais longas (YOSHIDA, 2012). O reator R-104 é descrito por Yoshida (2012) como sendo um arranjo paralelo de sete reatores tubulares contendo uma série de misturadores estáticos responsáveis pela homogeneização da massa reacional. Foi proposto um controle de temperatura no reator que age na alimentação de fluído que aquecimento que entra no reator.

O PLA passa então por um devolatizador DV-101 que terá como função gaseificar e recuperar o lactídeo não reagido no reator R-104. O lactídeo gaseificado será condensado por um trocador de calor TC-107 e armazenado por um vaso de processo V-112. O PLA será enviado para uma extrusora EX-101 que dará forma final ao produto. A figura 15 representa esse processo: 


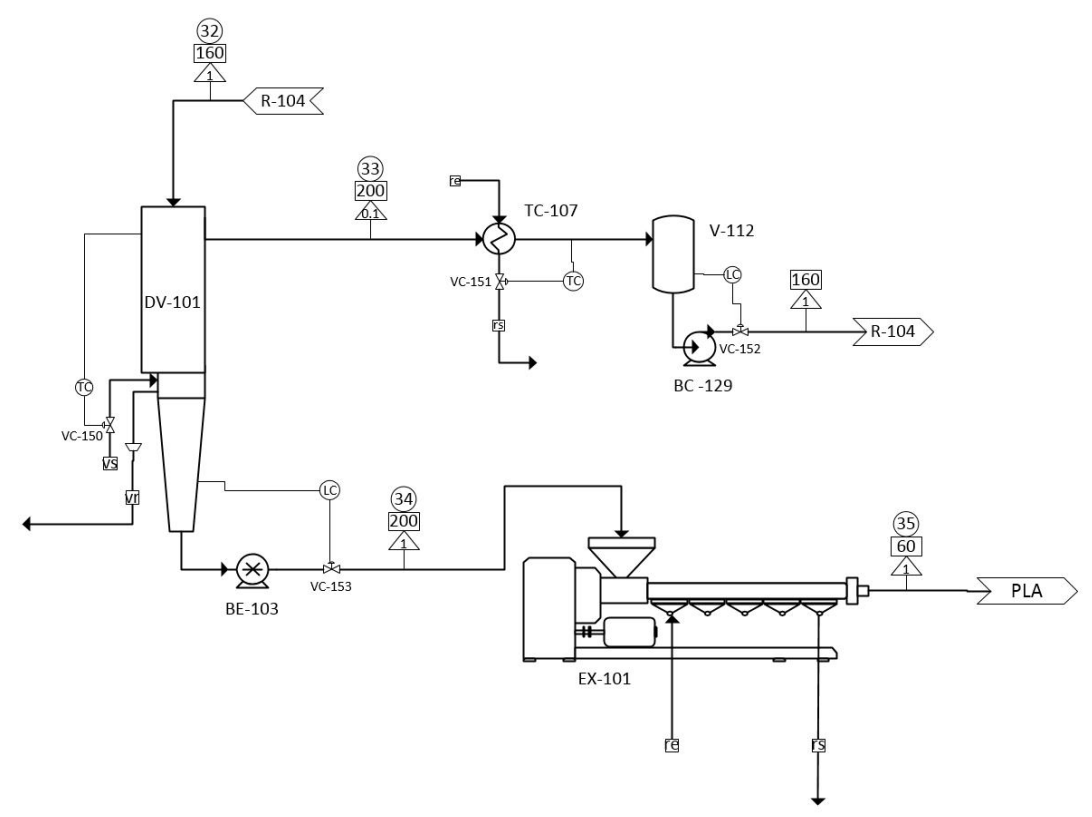

Figura 15 - Devolatizador e extrusora.

O devolatilizador DV-101 é aquecido através de uma corrente de vapor alimentada ao equipamento, sendo que seu controle de temperatura é realizado através da vazão de vapor em tal corrente. O PLA será transportado até a extrusora EX-101 através de uma bomba de engrenagem BE-103 que também terá como função a injeção do PLA no equipamento. A extrusora dará forma de pellets granulados ao PLA que então será ensacado.

\section{CONCLUSÃO}

A utilização de um rejeito industrial como matéria prima é de grande valor, tendo em vista que atualmente são utilizados vegetais ricos em amido, que geralmente tem alto valor agregado. Tornar o PLA mais competitivo a polímeros tradicionais é de suma importância para que haja maior adesão desse material pelo mercado.

O processo pode ser melhorado ou expandido em trabalhos futuros, tendo em vista que a substituição de equipamentos ou técnicas pode refletir em um maior rendimento ou economia. Tendo como exemplo o sistema de evaporadores de múltiplo efeito, que poderia ser substituído por métodos que exijam um menor grau de mecanização, e a purificação do ácido lático pela coluna de troca iônica, que pode operar apenas com uma baixa produção e poderia ser substituída por outras técnicas, como a recuperação do ácido lático por destilação.

Também vale destacar que o trabalho expandiu tecnologias de polimerização já existentes, principalmente a apresentada por Yoshida (2012), definindo equipamentos, operações unitárias e uma filosofia de instrumentação e controle. 


\section{AGRADECIMENTOS}

À Pontifícia Universidade Católica do Paraná (PUCPR), por disponibilizar a estrutura necessária para realização deste trabalho.

À Eugenia, Aurelio, e Juliana pelo apoio oferecido no dia-a-dia.

À Carol e Ângelo, pela ajuda e sugestões referentes ao trabalho.

E principalmente ao professor Carlos Eduardo Lunelli pelo ensinamento e empréstimo de seu conhecimento.

\section{REFERÊNCIAS}

BERNARDO, M. P.; Produção e purificação de $\mathbf{L}(+)$ ácido lático por Lactobacillus rhamnosus utilizando processo de batelada alimentada. 2014. 76 f. Dissertação (Mestrado em Ciências Biológicas-Microbiologia Aplicada) - Universidade Estadual Paulista, Rio Claro, SP, 2014.

CANEVAROLO JR., S. V. Ciência dos Polímeros. 2 ed. São Paulo: Artliber Editora, 2006.

CASTRO-AGUIRRE, E.; IÑIGUEZ-FRANCO, F.; SAMSUDIN, H.; FANG, X.; AURAS, R. Poly(lactic acid) - Mass production, processing, industrial applications, and end of life. Advanced Drug Delivery Reviews, v.107, p. 333-366, dez. 2016.

COSTA, C. M.; AZEVEDO, C. A.; AZEVEDO L. A.; LINS, M. F.; VEIGA, R. L.; LIMA, S. F. Soro do leite e os danos causados ao meio ambiente. X Encontro Brasileiro sobre Adsorção, 2014, Guarujá, SP.

EARL, R. L. Unit Operations in Food Processing. 2 ed. Oxford, England: Pergamon Press, 1983.

FARAH, S.; ANDERSON, D. G.; LANGER, R. Physical and mechanical properties of PLA, and their functions in widespread applications - A comprehensive review. Advanced Drug Delivery Reviews, v.107, p. 367-392, dez. 2016.

HAMAD, K.; KASEEM, M.; YANG, H. W.; DERI, F.; KO, Y. G. Properties and medical applications of polylactic acid: A review. eXPRESS Polymer Letters, Budapeste, Pest, Hungria, v. 9, n. 5, p. 435-455, Mai. 2015.

LOPES, M. S.; JARDINI, A. L.; FILHO, R. M. Synthesis and Characterizations of Poly (Lactic Acid) by Ring-Opening Polymerization for Biomedical Applications. CHEMICAL ENGINEERING TRANSACTIONS, v. 38, p. 331-336, jun. 2014.

MURARIU, M.; DUBOIS, P. PLA composites: From production to properties. Advanced Drug Delivery Reviews, v.107, p. 47-59, dez. 2016.

PAULO YOSHIDA. COMPANHIA REFINADORA DA AMAZÔNIA.. Processo de produção de poli (ácido lático) e reatores para utilização no referido processo. WO 2012021957 A1, 23 fev. 2012.

PRAZERES, A. R.; CARVALHO, F.; RIVAS, J. Cheese whey management: A review. Journal of Environmental Management, Berkeley, CA, USA, v. 110, p. 48-68, nov. 2012.

PRETULA, J.; SLOMKOWSKI, S.; PENCZEK, S. Polylactides-Methods of synthesis and 
characterization. Advanced Drug Delivery Reviews, v.107, p. 3-16, dez. 2016.

ROHLFES, A. L. B.; BACCAR, N. M.; OLIVEIRA, M. S. R.; MARQUARDT, L.; WEIS, L.; LOPES, L.; BLEY, D. E.; HOCHSCHEID, S. L. Aproveitamento de subproduto de agroindústrias do setor queijeiro para desenvolvimento de produtos alimentícios e redução de impacto ambiental. Tecno-Lógica, Santa Cruz do Sul, RS, v. 18, n. 1, p. 1318, mai. 2014.

SAINI, P.; ARORA, M.; RAVI KUMAR, M. N. V. Poly(lactic acid) blends in biomedical applications. Advanced Drug Delivery Reviews, v.107, p. 47-59, dez. 2016.

SIQUEIRA, A. M. O.; MACHADO, E. C. L.; STAMFORD, T. L. M. Bebidas lácteas com soro de queijo e frutas. Ciência Rural, Santa Maria, RS, v. 43, n. 9, p. 1693-1700, set. 2014.

SLOMKOWSKI, S.; PENCZEK, S.; DUDA, A. Polylactides-an overview. Polymers for Advanced Technologies, v. 25, n. 5, p. 436-447, mai. 2014.

WALAS, S. M; COUPER. J. R.; PENNEY, W. R.; FAIR, J. R. Chemical Process Equipment: Selection and Design. 3 ed. Oxford, England: Butterworth-Heinemann, 2012.

YOSHIMARA, Y.; NOJIRI, M.; ARIMOTO, M.; ISHIMOTO, K.; ASO, Y.; OHARA, H.; YAMANE, H.; KOBAYASHI, S. Green polymer chemistry: One-pot, metal-free synthesis of macromonomer via direct polycondensation of lactic acid and its radical polymerization to graft and comb polymers. Polymer, v. 90, p. 342-350, mai. 2016. 